\title{
Chapter 4 \\ Sustainability of Micro Hydropower \\ Generation in a Traditional Community of Indonesia
}

\author{
Tatsuro Sato and Jun'ichiro Ide
}

\begin{abstract}
Over 3 years, we undertook a micro hydropower (MHP) project in the Ciptagelar village, West Java, to improve the understanding and implementation of sustainable operations and management of MHP generation in remote rural areas, where the primary industry is farming and thus monetary incomes are low. First, we describe in this paper the history of setting up the research agenda to be tackled with the cooperation of governmental and nongovernmental stakeholders. Second, we report the current status of MHP plants and the related issues obtained through fieldwork and model simulations, in the context of culture, traditions, and society in the village. Finally, we propose guidelines to solve the issues and present the lessons learned and things scientists should pay attention to when proceeding with transdisciplinary research projects in remote rural areas. Through fieldwork and model simulations, we revealed issues related to budgeting and techniques for maintaining and operating MHP plants. We found that the village had difficulty in securing funds for repairing broken intake weirs, though it had funds to cover the general maintenance of the MHP plants. We also found that the intake weirs were vulnerable to large floods and that no accomplished technicians were available to operate MHP plants in the village properly. To solve these issues, we need to find ways to reinforce the intake weirs using local materials and increase monetary incomes by creating new industries based on the MHP generation while considering the cultural and traditional backgrounds of the remote rural areas.
\end{abstract}

Keywords Mountainous area - Off-grid power - Renewable energy $\cdot$ Rice paddy Sustainable infrastructure

\footnotetext{
T. Sato $(\bowtie)$

Disaster Risk Reduction Research Center, Graduate School of Engineering, Kyushu University, Fukuoka, Japan

J. Ide

Department of Applied Chemistry and Bioscience, Chitose Institute of Science and Technology, Chitose, Japan
} 


\section{Introduction}

Global energy demand nearly doubled from 1970 to 2003, increasing with population and economic growth. By 2040, it is expected to increase by $\sim 30 \%$ over current levels (International Energy Agency 2016). Developing countries are expected to account for $\sim 60 \%$ of the increase in energy demands as of 2030 . However, meeting these energy demands may be difficult because of continued dependence on finite fossil fuels. In addition, the use of fossil fuels emits large amounts of greenhouse gases into the atmosphere, resulting in severe climate change. The Paris climate agreement, an international framework for reducing greenhouse gas emissions starting in the year 2020, was signed on November 4, 2016. Nearly all countries, including major greenhouse-gas-emitting countries, participated in the agreement to stipulate efforts toward achieving the global, long-term goal of keeping the average temperature rise sufficiently below $2^{\circ} \mathrm{C}$, with each country submitting and updating emissions reduction targets as well as examining the global implementation status every 5 years. The first key to achieving the ambitious goal is to promote an energy mix that emphasizes renewable energy, in addition to energy saving and increased energy efficiency.

The introduction of distributed renewable energy production is essential for various reasons. First, geographically dispersed renewable energy promotes regional economic development. Local renewable energy is a sustainable regional resource and is an inexpensive form of energy for future use. Shifting from energy dependence on external sources to locally procured energy leads to the increase of fund circulation within the region, activation of the regional economy, and increased employment opportunities in the newly developed energy industry. Besides, renewable energies are more resilient against disasters compared with their nonrenewable counterparts. On March 11, 2011, the Great East Japan Earthquake and subsequent Fukushima Daiichi nuclear disaster shed light on the significant weaknesses of the existing electricity infrastructure. The damage to lifelines and power outages significantly affected the Japanese citizens; medical care, transportation, and industrial activity were all restricted. These experiences exposed the limitations of large-scale centralized power systems. Conversely, when the 2016 Kumamoto earthquake occurred, homes wherein photovoltaic power generators were installed received uninterrupted electricity supply, even during power grid failures.

Comprehensively considering these diverse positive impacts encourages the creation of sustainable energy systems. The policy framework that directly addresses these positive impacts is the 2030 Agenda for Sustainable Development, which lays out Sustainable Development Goals (SDGs), adopted by the UN Sustainable Development Summit held in September 2015. Of the 17 goals and 169 targets, Goal 7 relates specifically to energy, aiming at "ensuring access to affordable, reliable, sustainable, and modern energy for all" (United Nations 2019). As population increases and lifestyles change in developing countries, energy demands continue to increase. Sustainable energy supply is vital for eradicating poverty, establishing a stable environment that is resilient against disasters, and providing a culturally rich 
lifestyle. Discussions on a national level regarding power supply and energy mix have gradually accelerated; however, vested interests in the energy sector are great, and current political conditions pose difficulties in introducing significant top-down changes. On the other hand, at the Institute of Decision Science for a Sustainable Society (IDS3) in Kyushu University, we have collaborated with local communities to develop bottom-up sustainable social reforms. We hope that such individual challenges (learnings) encountered at the local level will be shared via the global network, leading to a big wave of support for a sustainable society.

Herein, the micro hydropower (MHP) project, which is an essential renewable energy source in the farming villages of Indonesia, is introduced. In this project, we aimed to answer the question, "how do we realize sustainable MHP generation in remote rural areas?". For this, we have investigated the current status of energy selfsufficiency in a traditional farming village located in the mountainous area in West Java, Indonesia, over 3 years. We describe the contents of our investigations and efforts in Indonesia in chronological order. We would also like to share crucial points to help conduct Future Earth research that orients the cooperation between scientists and social stakeholders.

\section{Case History}

\subsection{Phase I (2015): Setting Up the Research Agenda to be Tackled (Co-design)}

The Republic of Indonesia is located in East Asia and has the fourth largest population in the world. In recent years, its economic growth rate and consequently, energy demand has been rapidly increasing. On the other hand, it has many remote regional areas that are not electrified. This is because Indonesia is the world's largest archipelago state, which consists of more than 17,000 islands, and thus it is unfeasible to construct centralized power grids all over the country. Therefore, activities to electrify the remote off-grid areas are being promoted by using inexpensive techniques of MHP generation that have been developed in Indonesia.

MHP is one of the most widely introduced renewable energies in Indonesia (Sukarna 2012), because Indonesia has steep terrain and thereby has enormous potential for MHP generation, and because MHP does not need massive constructions like dams. The electrification rate in villages in Indonesia increased from $5 \%$ in 1978 to $62 \%$ in 1995 and reached approximately 82\% in 2000 (Nagai 1999; JICA 2005). In recent years, the introduction of feed-in tariff has accelerated the spread of renewable energy, such as MHP, in remote regional areas. However, during the rainy season, flood disasters frequently occur in the areas suitable for MHP and sometimes destroy the MHP generation facilities. Additionally, there are many cases where MHP is operated mainly by residents, and the destroyed MHP facility remains unrepaired because of insufficient budgeting (Ranzanici 2013). 
To narrow down the research topics for sustainable regional MHP generation, we contacted Bandung Hydro Association (Asosiasi Hidro Bandung: AHB), the central organization for MHP generation in Indonesia. Moreover, Kyushu University already had a cooperative relationship with AHB because of technology exchange. Initially, we tried to grasp the current status of MHP generation in remote areas in Indonesia. We conducted face-to-face interviews and discussions with several stakeholders: The Agency of Energy and Mineral Resources of West Java Province (Dinas Energi dan Sumber Daya Mineral Provinsi Jawa Barat: ESDM), Bandung Institute of Technology (Institut Teknologi Bandung: ITB), and local village leaders, operators, and managers who face the issues on MHP. It was found that in approximately half of the MHP facilities introduced in remote areas in Java, intake weirs, headrace channels, and penstocks were broken by flood and sediment disasters, and consequently, the MHP generation stopped (Rahadian 2016, personal communication). This rate of the stopped MHP facilities was consistent with Peters and Sievert (2014), who found that more than 20\% of the MHP facilities they visited were out of order.

Several economic, social, and environmental issues affect sustained operations of MHP generation in economically developing countries (Purwanto and Afifah 2016). However, few studies have conducted field investigations to clarify practical issues that MHP stakeholders face or have proposed ways of resolving such issues. We have co-designed the content of the transdisciplinary (TD) study on the issues that challenge sustainable MHP operations while closely cooperating with the stakeholders. We set a goal to make protocols for the rehabilitation of stopped MHP facilities and sustainable operations and management of MHP in remote areas. Next, we decided on the target field. ESDM introduced us to a remote mountainous village, Ciptagelar village, where residents conserve a traditional lifestyle and are selfsufficient in electricity supply from MHP generation. However, the village had some problems with the MHP system. We selected this village as the TD study area.

\subsection{Phase II (2016): Research Framework in the Ciptagelar Village (Co-design)}

Ciptagelar village is located in the mountainous area of Sukabumi District, West Java Province, Indonesia $\left(6^{\circ} 48^{\prime} \mathrm{S}, 106^{\circ} 30^{\prime} \mathrm{E} ; 1122 \mathrm{~m}\right.$ a.s.1.; Fig. 4.1), and is difficult to access especially during the rainy season. There are approximately 750 households (receiving electricity from four MHP plants) in the village, and it is the heart of the Sundanese ethnic group, the Kasepuhan adat community. It is estimated that approximately 16,000 people belong to that community and are distributed in the West Java and Banten Provinces (Suganda 2009). The highest leader of the Kasepuhan adat community, Abah Ugi (Abah means "a father" and plays the role of a king), lives in Ciptagelar village. 

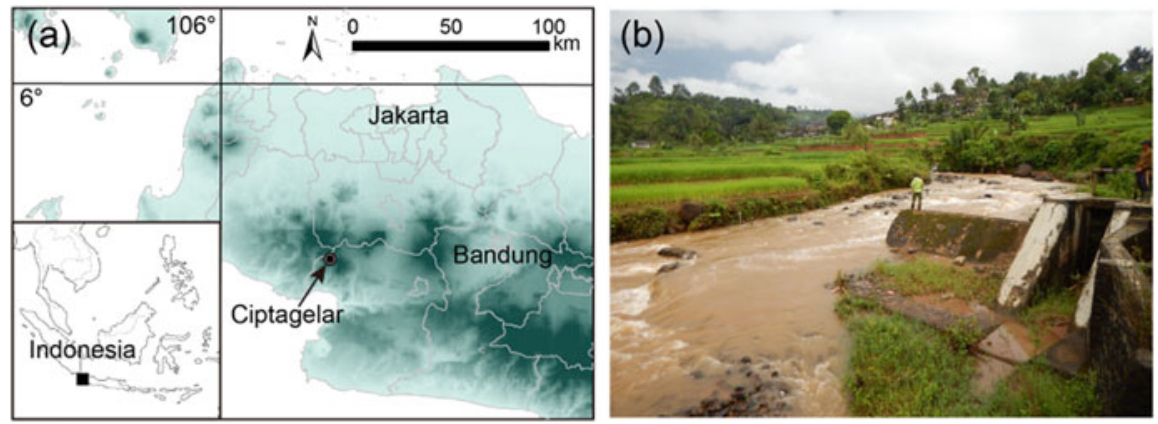

Fig. 4.1 (a) Location of the Ciptagelar village, Sukabumi, West Java Province, Indonesia. (b) Broken intake weir of the Situmurni No. 1 MHP (as of Mar. 2016)

Table 4.1 Properties of four MHP plants in Ciptagelar village

\begin{tabular}{l|l|l|l|l}
\hline $\begin{array}{l}\text { Name of MHP } \\
\text { plant }\end{array}$ & $\begin{array}{l}\text { Year of } \\
\text { construction }\end{array}$ & $\begin{array}{l}\text { Max. output } \\
(\mathrm{kW})\end{array}$ & $\begin{array}{l}\text { Broken parts } \\
\text { (times) }^{\mathrm{a}}\end{array}$ & Funders (at construction) \\
\hline Cicemet & 1997 & 60 & $\begin{array}{l}\text { Turbine (2) } \\
\text { Generator (2) } \\
\text { Controller (1) } \\
\text { Intake weir (1) }\end{array}$ & JICA (Japan) \\
\hline $\begin{array}{l}\text { Situmurni } \\
\text { No. } 1\end{array}$ & 2001 & 40 & $\begin{array}{l}\text { Turbine (1) } \\
\text { Bearing (?) } \\
\text { Belt (?) } \\
\text { Intake weir (?) }\end{array}$ & West Java Province \\
\hline Cibadak & 2012 & 60 & $\begin{array}{l}\text { Turbine (1) } \\
\text { Transformer } \\
(2)\end{array}$ & Local bank \\
\hline $\begin{array}{l}\text { Situmurni } \\
\text { No. 2 }\end{array}$ & 2013 & 45 & $\begin{array}{l}\text { Headrace chan- } \\
\text { nel (1) }\end{array}$ & $\begin{array}{l}\text { KOMIPO, KOIKA, } \\
\text { (Korea), IBEKA }\end{array}$ \\
\hline
\end{tabular}

${ }^{\mathrm{a}}$ Number of times that an issue with the part has caused the MHP plant to be out of operation

As the village is located along the boundary of Gunung Halimun National Park, in a steep mountainous area and difficult to access because of steep unpaved roads, power supply from the Indonesian government-owned power company (Perusahaan Listrik Negarandonesian: PLN) has been restricted. To compensate for the insufficient power supply in the village, four MHP facilities (Table 4.1) have been installed in sequential order since 1997 through the support of international donors, the local government, NGOs, and a local bank. The generated electricity is used for basic modern human needs, mainly electric lighting (Ide et al. 2018), which has replaced oil lamps. Other uses of electricity are watching television and using smartphones (i.e., charging their batteries), which provide residents information from outside of the village. However, as of March 2016, two of the four facilities (Situmurni No.1 and Cibadak) were out of operation because of disasters, such as massive floods, landslides, and thunderstorms caused by extreme weather conditions. 
In March 2016, we conducted a stakeholder meeting including the village residents, Abah, who is a proprietor of MHP in the village, and staff of the ESDM of West Java and AHB. Then we co-designed the framework of transdisciplinary research in this village, which aims to assess the vulnerability of MHP plants to disasters scientifically. We planned to make an actual rehabilitation plan for a stopped MHP plant (Situmurni No. 1) in collaboration with all the stakeholders, considering the village's history, characteristics, beliefs, and economic conditions.

However, early in the project, our research framework was forced to change. As soon as the investigation started toward the rehabilitation of the broken intake weir, the intake weir was reconstructed by a coal mining company, as a corporate social responsibility activity under the permission of Abah. This is because it had been 7 months since the intake weir was broken and the power supply to households stopped, and residents were demanding that electricity be restored to resume their normal lives. This suggests that electricity has already become an essential part of residents' lives. At that time, we had not built a trusting relationship with the community and the leader, Abah, and so we were not able to be involved in the rehabilitation efforts of the intake weir. The real world could not afford to wait for research results. The reconstruction of the intake weir was good news for the village. However, we were concerned about the fact that the structure and location of the reconstructed intake weir were the same as those of the previous one, which was vulnerable to massive floods. Risks remain that the intake weir will be broken again by floods.

We changed our research framework (re-co-design). We decided not to rehabilitate the intake weir with the stakeholders specifically but to present management methods for sustainable MHP plants from both sociological and engineering approaches.

\subsection{Phase III (2017): Learning the Context of the Ciptagelar Community (Co-production)}

To evaluate the vulnerability of MHP plants to disasters and build the countermeasures scientifically, we investigated the structure of the broken intake weir of an MHP plant. We additionally collected hydrological data such as rainfall and river flow data in 2017. Such research activities were conducted in collaboration with several stakeholders, including ESDM, ITB, AHB, and the local residents.

We also had repeated dialogue with residents and leaders in order to understand the culture, traditions, thought, industries, and economic conditions of the Ciptagelar community. This understanding is the foundation of sustainable MHP management and essential to building trust with the community (Fig. 4.2). We visited the village many times and sometimes participated in some critical traditional ceremonies relating to rice farming and Abah's birthday parties. 


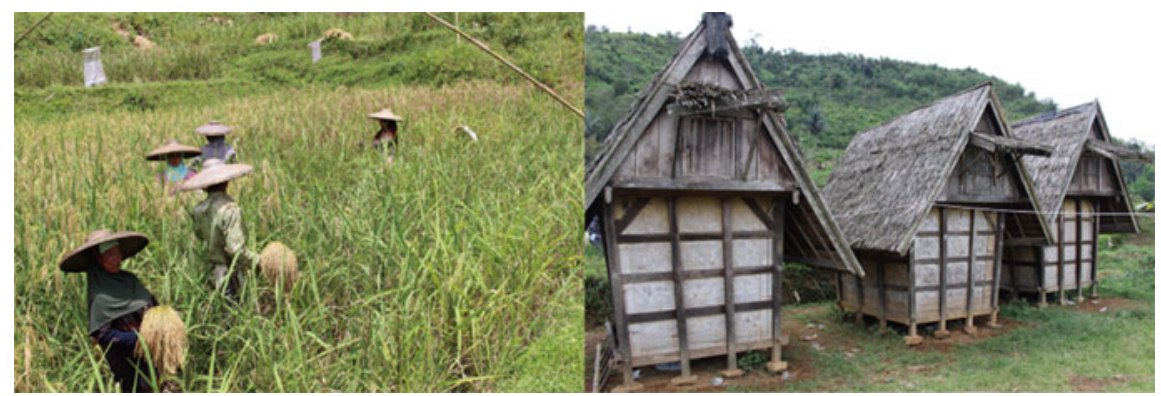

Fig. 4.2 Rice farming and the barns "Leuit" in Ciptagelar

Through the repeated dialogs, we could touch the deep traditional culture and understand the current socio-economic situation of the Ciptagelar community. The birth of the Kasephan ethnic group, to which the Ciptagelar village belongs, dates to 1368. Since then, the "Abah" has continued via a male patriarchy system. He administers religious services and magic rituals like a shaman in the community. $\mathrm{He}$ is the spiritual pillar of the community, and the community members have deep trust in him. Rice farming conducted cooperatively between residents is essential for the traditional livelihoods of the residents in Ciptagelar village (Fig. 4.2). The residents believe that rice is part of the sacred life, and they plant it for subsistence, but not for commercial use. They are not allowed to buy and sell the harvested rice, because selling rice is comparable to selling life for them. They plant and harvest rice only once a year, according to the natural rhythm, though it is possible to plant rice two or three times per year in the West Java Province. In Ciptagelar village, human beings are recognized as a part of nature and nature as "Mother Earth" (Sato et al. 2017). Thus, residents do not use pesticides that kill living organisms in rice farming. Ten percent of the harvested rice is stored every year in unique barns called "Leuit," which is a symbol of the village (Fig. 4.2), to provide food in case of a poor harvest year. Leuit is also a sacred place, and it exists under the thought that the paddy must not be eradicated but be kept alive with the same importance as that of human life. Residents in Ciptagelar village have the "thought of pair," which is a philosophy that objects or things are a pair or have two poles, such as man and woman or the sun and the moon. Based on this thought, they introduce modern techniques, that is, electricity, while also recognizing the importance of the traditional livelihood.

Thus, the main livelihood in the Ciptagelar village is rice cultivation, but the sale of rice is prohibited. As a result, the source of cash income in the village is limited to the sale of agricultural products, such as Java sugar made from the sap of sugar palm, and construction labor. For this reason, many village residents migrate to the Banten Province to work as gold miners or to large cities such as Jakarta to work as construction laborers or housekeepers. 


\subsection{Phase IV (2018): Scientific Outcomes Revealing the Sustainability Issues of MHP Plants in Ciptagelar (Co-production)}

Accurate assessment of flood risk is essential for the sustainability of MHP plants in Ciptagelar. Several studies on flood risk assessments have valued the importance of technical and scientific approaches (Merz et al. 2014; Kellermann et al. 2015). In general, the risk assessment and the choice of preventive actions are based on several methods such as flood mapping, which is a crucial element of flood risk management. In order to help the stakeholders who were not familiar with technology and science understand the issues more clearly, flood mapping was selected to show the flood risk visually.

Based on the collected hydrological data, we constructed a runoff model on the relationship between rainfall and river flow, and the $2 \mathrm{D}$ flood simulation model (using Nays2Dflood solver in the iRIC software, https://i-ric.org/en/) that shows the spatial flood risk (Fig. 4.3). At first, the 2D flood model was developed only for one MHP plant (Situmurni No. 1 power plant), which had been out of operation because of damage to the intake weir at the start of this project. According to the request from stakeholders including the residents, we expanded the model to all four MHP plants in Ciptagelar village. In the development of the 2D flood model, drone photogrammetry for making high-resolution digital elevation data was conducted with stakeholders. Combining the frequency analysis using long-term public observation data

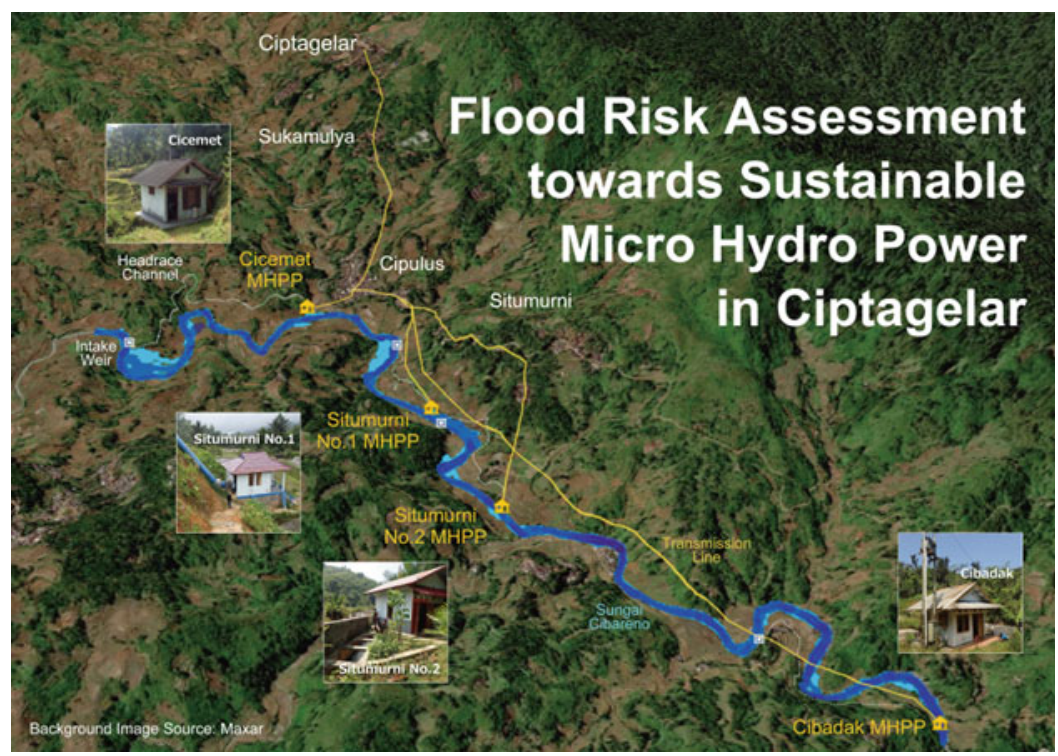

Fig. 4.3 Scientifically analyzed flood risk map in Ciptagelar, shared by stakeholders. Background image from (C) Maxar 
on rainfall, we could make the flood risk map in return periods covering all MHP plants. This map indicated that some MHP plants were vulnerable to floods.

Also, our investigations on the socio-economic issues underscored the difficulty for the village to secure budgets to repair and maintain the MHP facilities. The operators and Abah told us that some part of the facilities in all four MHP plants had been broken because of disasters, operation mistakes, and other causes and were replaced with a new one by Abah's borrowing money from banks and other companies. Previous studies pointed out that most of the village communities in remote areas have difficulty in permanently securing budgets for repairing and replacing parts of MHP facilities and generators because their primary industry is agriculture, which provides little monetary income (Yasunaga and Nishio 2001; Ranzanici 2013; Purwanto and Afifah 2016). Therefore, the community has no choice but to rely on external grants and donors to determine whether they can repair the broken facilities, as is the case in other developing countries (e.g., Palit and Chaurey 2011). These facts are true in the case of Ciptagelar village. On the other hand, it was hard for the donors to cover the cost of repairing the broken or damaged facility, though they support the construction cost as a startup of the MHP project because of the issue of equity and unclear ownership (West Java Province government has started to subsidize the repair of broken MHP plants).

In many MHP projects in developing countries, donors tend to focus on the construction of new power plants in places that have never had electricity (Urmee and Md 2016). However, once an MHP facility is installed, the responsibility of its operation and maintenance are often handed over to the community. Eventually, the project fails because the community does not have a sufficient maintenance budget. Our detailed survey clarified the electricity bill payments received from all households for the electricity supplied from the four MHP plants and the cost of maintenance including labor costs. It indicates that minimum maintenance can be performed based on the current electricity bill collection amount. However, this amount is not sufficient to cope with severe damage caused by large-scale failure or disaster.

\section{Exploring Measures to Solve the Issues}

From the issues as mentioned above related to operations and management of MHP in Ciptagelar village, we aimed to rehabilitate the stopped MHP facility, in consideration of the sustainability of MHP and the regional development. Specifically, we tried to support residents in starting new industries based on the MHP generation and thereby increase monetary income for maintaining MHP. Furthermore, we intended to increase job opportunities by creating new industries and thereby activate the regional economy and development. This rehabilitation should be operated mainly by the residents in the village and therefore should be conducted based on the 
combination of traditional and cutting-edge technologies, while respecting backgrounds, such as culture, tradition, and society of all stakeholders.

To reduce the risks and prepare for repairing the MHP facility in the future, we need to find ways of securing the budgets for the maintenance of MHP. Saito and Takahata (2004) proposed that part of electricity charges from residents should be accumulated as budgets for repairing the MHP facility. However, residents' income is generally much lower in the remote areas where the off-grid electrification was applied, and there are few sources of monetary income (e.g., Nagai 1999). In Ciptagelar village, there are limited sources of monetary income, that is, sales of agricultural productions, such as palm sugar and coffee beans. Therefore, if a high price is set for the electricity charges to secure the funds for repairs and it exceeds the residents' capability to pay, it cannot be adequately collected (Yasunaga and Nishio 2001).

We described earlier a way of securing the budgets by creating new industries based on MHP. This was also proposed by other previous studies (Saito and Takahata 2004; Ranzanici 2013). However, there is a deeply penetrated philosophy, "thought of a pair," in Ciptagelar village. Abah and residents think that they have to conserve their traditional livelihood as they integrate new technologies into their lives. The generated electricity is applied to the process of coffee beans, which is a main agricultural product in the village, and the monetary income generated through their sale is used for maintaining MHP facilities. However, this monetary amount is not sufficient because the production of coffee beans is limited. On the other hand, residents do not conduct a single plantation of coffee trees for increasing monetary income because of their philosophy (Sato et al. 2017). The industrial structure in the village should be changed to generate sufficient monetary income to cover the maintenance expenses of the MHP facilities. However, this is unfeasible in the village because it would change the unique traditions and livelihood, which would lead to the destruction of the psychological culture.

\section{Concluding Remarks and Perspectives}

In order to use and operate MHP generation in the local communities in a sustainable manner, both technical and financial aspects need to be addressed. As a result of a detailed investigation of the operation and maintenance status of MHP plants, it was found that the necessary maintenance costs can be derived from the residents through electricity bill payments. On the other hand, it was also found that once the plant was destroyed by natural disasters such as floods, funds could not be secured to restore or recover it. Therefore, in hydrological observations at the planning stage of MHP plants, it is necessary to precisely estimate not only low flow conditions, which strongly affect the amount of power generation, but also high flow conditions, which can damage or destroy the MHP plant. Also, it is necessary to create a countermeasure plan for flood risks, such as reinforcement of the intake 
weir. We are working closely with the West Java Provincial Government and are planning a budgetary backup for the countermeasures.

It turned out that errors in operation could often damage the MHP plant. The improvement of the skills of the operators in remote rural communities is the key to the sustainability of MHP generation. It is vital to build a cooperative relationship between NPOs in urban areas, such as AHB, Japanese engineers, and residents, and thereby share knowledge and technology over a long period.

\section{Lessons Learned}

1. Work together, learn together:

- Researchers tend to replace practical issues with the issues related to their fields of expertise, but they should think deeply about the true nature of the issues with local people. In other words, researchers should sincerely face the issues in which local people take a deep interest.

- To understand the true nature of the issues, researchers should frequently visit the site and thereby build a trusting relationship with local people.

2. Building a network flexibly:

- To grasp the true nature of practical issues and explore measures to solve them under changing social conditions, transdisciplinary approaches are needed; researchers need cooperation from several stakeholders. On the other hand, the relationships between stakeholders change with time, and stakeholders themselves change according to the stages of solving issues. Thus, researchers need to respond flexibly to their changes.

3. Practical wisdom:

- Problem-based research projects are not necessarily generalized; a case-bycase problem resolution is needed according to local and/or social situations.

- An accumulation of case studies is required so that everyone can access them for reference.

Acknowledgments This work was supported in part by the Program for Leading Graduate Schools from the JSPS (Graduate Education and Research Training Program in Decision Science for a Sustainable Society), a grant for Future Earth Study from the JST-RISTEX (JPMJRX16F1), the Grant-in-Aid for Scientific Research from the JSPS (\#JP15K16115; \#JP18K11623), and a research grant from the Mitsui \& Co. Environment Fund (\#R19-0026). We would like to acknowledge Dr. Nariaki Onda, Mr. M. Alhaqurahman Isa, Ms. Asari Takada, and other students in the Institute of Decision Science for a Sustainable Society, Kyushu University, for helping us with our field survey, and members of the Dinas ESDM-Jabar and AHB for their kind cooperation during the field survey. We also extend sincere thanks to the Ciptagelar community. 


\section{References}

Ide J, Sato T, Fujiwara T, Fuse K, Kikuchi A, Yokota F, Isa MA, Rahadian F, Tjia YF, Shimatani Y (2018) Current status and issues on sustained management and operations of micro hydropower generation in the remote area in Indonesia: a case study in the Ciptagelar village. J Jpn Soc Hydrol Water Res 31:262-269

International Energy Agency (2016) World energy outlook 2016. France, p 684

JICA (2005) Prior assessment report of regional electrification in Indonesia, p 50

Kellermann P, Schöbel A, Kundela G, Thieken AH (2015) Estimating flood damage to railway infrastructure - the case study of the March River flood in 2006 at the Austrian Northern Railway. Nat Hazards Earth Syst Sci 15:2485-2496

Merz B, Aerts J, Arnbjerg-Nielsen K, Baldi M, Becker A, Bichet A, Blöschl G, Bouwer LM, Brauer A, Cioffi $\mathrm{F}$ et al (2014) Floods and climate: emerging perspectives for flood risk assessment and management. Nat Hazards Earth Syst Sci 14:1921-1942

Nagai M (1999) Efforts toward regional electrification in Indonesia. Elect Power Civil Eng 279:134-136

Palit D, Chaurey A (2011) Off-grid rural electrification experiences from South Asia: status and best practices. Energy Sustain Dev 15:266-276

Peters J, Sievert M (2014) Impact evaluation of Netherlands supported programmes in the area of Energy and Development Cooperation in Indonesia the provision of electricity to rural communities through micro-hydro power. International Institute of Social Studies, $\mathrm{p} 76$

Purwanto WW, Afifah N (2016) Assessing the impact of techno socioeconomic factors on sustainability indicators of microhydro power projects in Indonesia: a comparative study. Renew Energy 93:312-322

Ranzanici A (2013) Sustainability comparison between EnDev and non-EnDev micro-hydro power (MHP) in Indonesia. Universidad Politecnica de Madrid, p 101

Saito Y, Takahata M (2004) Residents-participatory regional electrification projects of microhydropower in Indonesia. Elect Power Civil Eng 313:123-125

Sato T, Ide J, Isa MA, Rahadian F, Fujimoto T, Shimatani Y (2017) A challenge for sustainable electrification, respecting the local tradition in Ciptagelar Village, West Java, Indonesia: Complementary Approach with a Private Company. Energy Procedia 141:368-372

Suganda KU (2009) The Ciptagelar Kasepuhan indigenous community, West Java: developing a bargaining position over customary forest. In: Forests for the future: indigenous forest management in a changing world. AMAN-DTE, Jakarta, pp 27-62

Sukarna ID (2012) Energy efficiency and renewable energy in Indonesia. Available at http://energyindonesia.com/03dge/0120720. Accessed 6 December 2017

United Nations (2019) Report of the secretary-general on the work of the Organization. United Nations Publications, New York, $\mathrm{p} 120$

Urmee T, Md A (2016) Social, cultural and political dimensions of off-grid renewable energy programs in developing countries. Renew Energy 93:159-167

Yasunaga R, Nishio F (2001) A consideration on ways of setting electricity charges in regional electrification - a case study of small hydropower electrification in the regional village in Indonesia. Elect Power Civil Eng 296:170-175 
Open Access This chapter is licensed under the terms of the Creative Commons Attribution 4.0 International License (http://creativecommons.org/licenses/by/4.0/), which permits use, sharing, adaptation, distribution and reproduction in any medium or format, as long as you give appropriate credit to the original author(s) and the source, provide a link to the Creative Commons license and indicate if changes were made.

The images or other third party material in this chapter are included in the chapter's Creative Commons license, unless indicated otherwise in a credit line to the material. If material is not included in the chapter's Creative Commons license and your intended use is not permitted by statutory regulation or exceeds the permitted use, you will need to obtain permission directly from the copyright holder. 